\title{
BIOPROSPECÇÃO DE FUNGOS ENDOFÍTICOS ASSOCIADOS À Physalis peruviana Linnaeus. COM ATIVIDADE ANTIMICROBIANA.
}

\author{
$\underline{\text { Jade Ribeiro Carneiro1; }}$ Angélica Maria Lucchese²; Hianna Almeida Câmara Leite ${ }^{3}$ e \\ Luís Fernando Pascholati Gusmão ${ }^{4}$ \\ 1. Bolsista PIBIC/CNPq, Graduando em Bacharelado em Ciências Biológicas, Universidade Estadual de Feira de Santana, e- \\ mail: rc.jade@hotmail.com \\ 2. Orientador, Departamento Exatas, Universidade Estadual de Feira de Santana, e-mail: \\ anlucc@uefs.br \\ 3. Participante do projeto, Departamento de Ciências Biológicas, Universidade Estadual de Feira de Santana, e-mail: \\ leite.hianna@gmail.com \\ 4. Participante do projeto, Departamento de Ciências Biológicas, Universidade Estadual de Feira de Santana, e-mail: \\ lgusmao@uefs.br
}

PALAVRAS-CHAVE: Physalis peruaviana; Acremonium; compostos fenólicos.

\section{INTRODUÇÃO}

As plantas medicinais vêm sendo reconhecidas como uma fonte de fungos endofíticos produtores de metabólitos secundários de importância farmacêutica. A flora brasileira dispõe de diversas plantas de aplicação medicinal, a maioria delas de ação ainda pouco caracterizada cientificamente e inexploradas quanto a microbiota endofítica (SHAN et al, 2012).

Physalis peruviana é uma espécie da família Solanaceae conhecida pelos seus frutos comestíveis e uso medicinal tradicional. Os compostos bioativos majoritários da espécie são os vitanolídeos e as fisalinas (A, B, D e F) que apresentam atividade antimicrobiana, antiinflamatória e anticâncer já descritas (CARRILO-PERDOMOA et al., 2015).

Considerando a importância medicinal desta espécie e tendo em vista os resultados promissores envolvendo a relação mutualística planta-hospedeiro, este trabalho tem como objetivo a avaliação da atividade antimicrobiana frente aos patógenos Staphylococcus aureus (CCMB263 resistente a novobiocina), Escherichia coli (CCMB261 resistente a sulfonamida) e Candida albicans CCMB286 (resistente a fluconazol e anfotericina B) e a avaliação do perfil cromatográfico de fungos endofíticos com ação antimicrobiana.

\section{MATERIAL E MÉTODOS}

\section{Coleta de material vegetal e isolamento, purificação e identificação da microbiota endofítica fúngica}

Três indivíduos da espécie $P$. peruviana $\mathrm{L}$. foram coletados em campo de cultivo no Horto Florestal da Universidade Estadual de Feira de Santana (UEFS). A desinfecção das folhas, flores e frutos foi realizada segundo Wijeratne et al., (2014) com modificações. Para cada indivíduo, as três partes foram submetidas a desinfestação superficial através da sequência de $95 \%$ EtOH por 30 s, $0,5 \% \mathrm{NaOCl}$ por 2 min e $70 \%$ EtOH por 2 min. Para caule e raiz, foi realizada segundo Marquez-Santacruz, et al., (2010). Os caules e raízes foram previamente cortados e submetidos a desinfestação superficial através da sequência de $70 \%$ EtOH por $3 \mathrm{~min}, 2,5 \% \mathrm{NaOCl}$ por $3 \mathrm{~min}$, e $70 \% \mathrm{EtOH}$ por $30 \mathrm{~s}$. Após secagem da superfície, as partes foram novamente cortadas e três pedaços de cada triplicata colocados em placa de petri contendo meio BDA acrescido de Cloranfenicol $(100 \mathrm{mg} / \mathrm{ml})$ e incubadas em Estufa de Crescimento à $28^{\circ} \mathrm{C}$. Cada colônia emergente foi repicada para novas placas contendo meio 
BDA até a verificação da pureza. Todos os fungos foram preservados e depositados na Micoteca do LAPRON/UEFS. A identificação morfológica dos isolados selecionados foi realizada no Laboratório de Micologia-LAMIC/UEFS.

\section{Screening da atividade antimicrobiana}

Para avaliação da atividade antimicrobiana, todos os isolados foram submetidos ao método de difusão em disco (Kirby \& Bauer, 1960), com modificações contra Staphylococcus aureus CCMB263 (resistente a novobiocina), Escherichia coli CCMB261 (resistente a sulfonamida) e Candida albicans CCMB286 (resistente a fluconazol e anfotericina B) provenientes da Coleção de Cultura de Microorganismos da Bahia-CCMB.

Produção dos extratos

Os fungos 1F13, 1R14 e 1C13, que apresentaram maior halo de inibição na difusão em disco, foram cultivados em caldo Batata Dextrose (HiMedia $\left.{ }^{\circledR}\right)(1,25 \mathrm{~L} 5 \times 250 \mathrm{~mL}$ ) em Shaker, a $150 \mathrm{rpm} \mathrm{e} 30^{\circ} \mathrm{C}$, até zerar o nível de glicose. O micélio foi removido por filtração e os metabólitos presentes no meio líquido foram extraídos com acetato de etila 1:1. Para obtenção dos extratos brutos secos, o solvente foi removido por evaporação sob pressão reduzida em evaporador rotatório. Extratos a partir dos meios não fermentados também foram produzidos como controle.

\section{Determinação da Concentração Inibitória Mínima (CIM) e Concentração Bactericida Mínima (CBM) e Concentração Fungicida Mínima (CFM)}

Para a determinação do CIM, foi executada microdiluição em caldo, seguindo as normas da CLSI. Foram utilizadas as mesmas cepas patogênicas da difusão em disco. Controles do meio $1 \mathrm{x}$ concentrado, 2x concentrado, dos micro-organismos, do DMSO, do antibiótico Cloranfenicol [6 ug/uL] e Nistatina [2 ug/uL] foram feitos. Para revelação, foi utilizado Resazurina 0,01\%. A determinação da CBM/CFM foi feita após a revelação, $1 \mathrm{uL}$ de cada poço em que não houve crescimento bacteriano foi plaqueado em placas de petri contendo Agar MH. A menor concentração em que não houve crescimento é a CBM/CFM.

\section{Perfil químico}

Perfil químico foi avaliado através da cromatografia em camada delgada (CCD) em placas de sílica com os reveladores Anisaldeido/Ácido Sulfúrico (AS) para revelação de terpenos e esteroides, Liebermann-Burchard (LB) para triterpenos e esteróides, Hidróxido de Potássio (KOH) para antronas, antraquinonas e cumarinas, Dragendorff (DRG) para alcaloides e Produtos naturais (NP/PEG) para revelação de compostos fenólicos e flavonoides (WAGNER E BLADT, 2001).

\section{RESULTADOS E DISCUSSÃO}

Um total de cinquenta fungos endofíticos foi recuperado de folhas, caules, raízes, flores e frutos com as respectivas Taxas de Colonização de 93,3\%, 96,4\%, 96,4\%, 83,3\% e $66,6 \%$. Esse é o primeiro relato na literatura de isolamento de fungos endofíticos filamentosos e culturáveis associados à Physalis peruviana.

Para triagem da atividade antimicrobiana, todos os isolados foram submetidos ao método de difusão em disco. Doze isolados (24\%) apresentaram atividade antimicrobiana para pelo menos um dos microrganismos patogênicos testados. Para $S$. aureus o isolado $1 \mathrm{~F} 13$ apresentou maior halo de inibição $(17 \mathrm{~mm})$, seguido por 1R14 $(16 \mathrm{~mm})$ e $1 \mathrm{C} 13(9 \mathrm{~mm})$, para 
E. coli o isolado $3 \mathrm{~F} 31$ apresentou maior halo de inibição $(11 \mathrm{~mm})$ e para $C$. albicans, novamente o isolado 1F13 apresentou maior halo de inibição (12 mm).

Como pode ser visto na figura 1, os isolados 1F13, 1R14 e 1C13, que apresentaram resultados positivos no teste de difusão em disco, são produtores de pigmentos. Os pigmentos fúngicos possuem um amplo esprectro de aplicações na indústria de cosméticos, téxtil, de alimentos e farmacêutica, essa última graças ás suas atividades biológicas como ação antibacteriana e antifúngica (Zhou \& LIU, 2010).

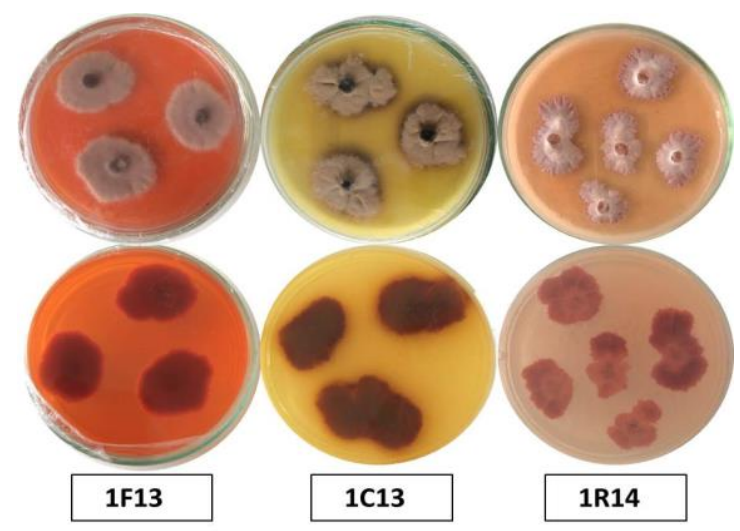

Figura 1. Morfologia externa e produção de pigmentos das culturas dos isolados 1F13, 1C13 e 1R14 após duas semanas de incubação.

Os isolados 1F13, 1R14 e 3F31 foram, respectivamente, identificados pela sua morfologia como Acremonium-like sp1, Acremonium-like sp2 e Fusarium sp1. O fungo 1C13 não foi identificado, pois o micélio se manteve estéril.

Como pode ser visto na tabela 1, a CIM, CBM e CFM dos extratos dos fungos 1F13, $1 \mathrm{R} 14$ e 1C13 foi determinada frente as mesmas cepas patogênicas do teste de difusão em disco. O alto valor de CIM encontrado para E. coli pode ser devido a membrana externa presente em bactérias Gram-, que aumentam a impermeabilidade da membrana. O isolado Acremonium-like sp1 (1F13) apresentou o menor valor de CIM para C. albicans [60 ug/uL] e menor valor de CIM para S. aureus $[120 \mathrm{ug} / \mathrm{uL}]$. Espécies do gênero Acremonium são reportadas como fonte de metabólitos ativos com forte atividade antibacteriana e antifúngica, exemplos desses compostos ativos isolados são o ácido fusídico, cefalosporina $\mathrm{C}$ e isoridina $\mathrm{A}$ (TIAN, LAI \& ZOU, 2017).

Tabela 2. Atividade antimicrobiana dos extratos dos isolados 1F13, 1R14 e 1C13.

\begin{tabular}{cccccccr}
\hline & $\begin{array}{c}\text { Cloranfenicol } \\
\text { Nistatina }\end{array}$ & \multicolumn{2}{c}{1 F13 } & & 1R14 & \multicolumn{2}{c}{1 1313 } \\
\hline Micro- & CIM & CIM & CBM & CIM & CBM & CIM & CBM \\
organismo & & & CFM & & CFM & & CFM \\
\hline S. aureus & $<0,01$ & $\mathbf{0 , 1 2}$ & 0,43 & 0.99 & 1,98 & 0,21 & 0,43 \\
E. coli & 0,33 & 2,01 & 4,03 & 2,01 & 4,03 & 1,72 & 1,72 \\
C. albicans & $<0,01$ & $\mathbf{0 , 0 6}$ & 0,50 & 0,12 & 2,01 & 1,72 & 6,90 \\
\hline
\end{tabular}


CIM - Concentração inibitória Mínima. CBM/CFM - Concentração Bactericida/FungicidaMínima. As concentrações de CIM e CBM/CFM dos extratos e cloranfenicol estão expressas em mg.mL ${ }^{-1}$ e nistatina em L.mL ${ }^{-1}$.

A avaliação do perfil químico através da CCD indicou a presença de terpenos e esteroides para todos os três extratos avaliados e presença de compostos fenólicos apenas para o isolado 1F13. Cerca de 356 metabólitos já foram isolados de espécies do gênero Acremonium e terpenos e esteroides estão entre eles. Flavonoides ainda não foram isolados, mas indicativo da sua presença nesse gênero já foi reportada ( SUGIHARTO et al., 2016).

\section{CONSIDERAÇÕES FINAIS}

Os fungos endofíticos Acremonium-like sp1 (1F13), Acremonium-like sp2 e $1 \mathrm{C} 13$ se revelaram fontes promissoras de metabólitos secundários com atividade antimicrobiana. $\mathrm{O}$ isolamento dos compostos presentes no extrato bruto do isolado Acremonium-like sp1 (1F13), que apresentou menor valor de CIM para dois patógenos já está sendo realizado, entretanto trabalhos futuros serão necessários para identificação desses compostos e elucidação dos mecanismos de ação das moléculas ativas.

\section{REFERÊNCIAS}

CARRILO-PERDOMOA E, ALLERA A, CRUZ-QUINTANAB SM, GIAMPIERIC F, ALVAREZ-SUAREZB JM. 2015. Andean berries from Ecuador: A review on Botany, Agronomy, Chemistry and Health Potential. Journal of Berry Research. (5): 49-69.

MARQUEZ-SANTACRUZ HA, HERNANDEZ-LEON R, OROZCO-MOSQUEDA MC, VELAZQUEZ-SEPULVEDA I, SANTOYO G. 2010. Diversity of bacterial endophytes in roots of Mexican husk tomato plants (Physalis ixocarpa) and their detecton in the rhizosphere. Genetics and Molecular research. (9): 2372-2380.

SHAN, T. et al. 2012. Antibacterial activity of the endophytic fungi from medicinal herb, Macleaya cordata. African Journal of Biotechnology. 11(19): 4354-4359.

SUGIHARTO S, YUDIARTI T, ISROLI I. 2016. Assay of antioxidant potential of two filamentous fungi isolated from the Indonesian fermented dried cassava. Antioxidants.(5): 1-6. TIAN L, LAI D, ZHOU L. 2017. Secondary metabolites from Acremonium fungi: Diverse structures and bioactivities. Mini-reviews in Medicinal Chemistr. (17): 603-632.

WAGNER, H.; BLADT, S. 2001. Plant Drug Analysis, a thin layer chromatografy atlas. Springer. Second edition.

WIJERANI, E.M ET AL. 2014. Thielavialides A-E, Nor-spiro-azaphilones and Bisspiroazaphilone from Thielavia sp. PA001, an endophytic fungus isolated from Aeroponically gown Physalis alkekengi. Journal of Natural Products. (77): 1467-1472.

ZHOU ZY, LIU JK. 2010. Pigments of fungi (macromycetes). Natural Products Report. (27) 1531-1570. 